Open Access

\title{
Extracorporeal membrane oxygenation line-associated complications: in vitro testing of cyanoacrylate tissue adhesive and securement devices to prevent infection and dislodgement
}

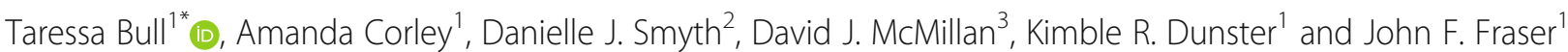

\author{
*Correspondence: Taressa.Bull@ \\ health.qld.gov.au \\ ${ }^{1}$ Critical Care Research Group, The \\ Prince Charles Hospital and \\ University of Queensland, Level 3 \\ Clinical Sciences Building, Rode Rd \\ Chermside 4032, Queensland, \\ Australia \\ Full list of author information is \\ available at the end of the article
}

\begin{abstract}
Background: Extracorporeal membrane oxygenation (ECMO) delivers cardiac and/or respiratory support to critically ill patients who have failed conventional medical therapies. If the large-bore cannulas used to deliver ECMO become infected or dislodged, the patient consequences can be catastrophic. ECMO cannula-related infection has been reported to be double the rate of other vascular devices (7.1 vs 3 . 4 episodes/1000 ECMO days respectively). The aim of this study was to assess the ability of cyanoacrylate tissue adhesive (TA) to inhibit bacterial growth at the ECMO cannulation site, and the effectiveness of TA and securement devices in securing ECMO cannulas and tubing.

Methods: This in vitro study tested the (1) antimicrobial qualities of TA against standard transparent dressing with ECMO cannula; (2) chemical compatibility between cannula, TA and removal agent; (3) pull-out strength of transparent dressing and TA at the cannula insertion site; and (4) pull-out strength of adhesive bandage and commercial sutureless securement devices (SSDs) on circuit tubing. Fisher's exact test was used to evaluate differences in bacterial growth observed between the transparent dressing and TA groups. Data from mechanical testing were analysed using one-way ANOVA, followed by Tukey's multiple comparison test or $t$ test as appropriate. Statistical significance was defined as $p<0.05$.

Results: No bacterial growth occurred under TA-covered cannulas compared with transparent dressing-covered cannulas $(p=0.002)$. Compared to plates lacking TA or transparent dressing, growth was observed at the insertion point and under the dressing in the transparent dressing group; however, no growth was observed in the TA group $(p=0.019)$. TA did not weaken the cannulas; however, the TA removal agent did after 60 min of exposure, compared with control $(p<0.01)$. Compared with transparent dressing, TA increased the pull-out force required for cannula dislodgement from the insertion point $(p<0.0001)$. SSDs significantly increased the force required to remove the tubing from the fixation points compared with adhesive bandage $(p<0.01)$.

(Continued on next page)
\end{abstract}


(Continued from previous page)

Conclusions: Our findings suggest that the combined use of TA at the cannula insertion site with a commercial device for tubing securement could provide an effective bedside strategy to prevent or minimise infection and line dislodgement.

Keywords: Extracorporeal membrane oxygenation, Cyanoacrylate, Tissue adhesives, Securement, Catheter-related infections

\section{Background}

Extracorporeal membrane oxygenation (ECMO) is a form of cardiopulmonary bypass used to support patients with severe cardiac and/or respiratory failure who have failed maximal conventional medical management $[1,2]$. Nosocomial infection is one of the most frequent and serious complications of ECMO [3, 4]. It is often difficult to treat [5] and has been reported in up to 64\% of ECMO patients [4]. Infections acquired whilst on ECMO are associated with increased durations of ECMO support and ventilatory support [3, 4, 6-9], and longer intensive care unit and hospital lengths of stay $[4,10]$. Poorer prognosis has also been reported in the paediatric population [11]. ECMO patients are a high-risk group for nosocomial bloodstream infections, which is partly attributable to the large-bore ECMO cannulas and multiple standard invasive devices needed to manage these critically ill patients $[3,10]$. Bloodstream infection rates on ECMO range from 3 to 19 per 1000 ECMO days $[3,4,7,8,10]$. Less frequently reported but equally important is the risk for localised cannula infection. ECMO cannula-associated infection prevalence ranges between 10 and $17 \%[4,12,13]$, with double the rate of infection associated with ECMO cannulas compared with other vascular devices (7.1 vs 3.4 episodes/1000 ECMO days respectively) [4].

ECMO lines (i.e. cannulas and associated tubing) are key components of the extracorporeal circuit but are associated with a large number of the causes of morbidity. Effective securement of these lines to a surface, such as the patient's limb, is necessary to prevent line movement, malposition or kinking that can precipitate obstruction, low circuit flow and poor venous return, all of which compromise the effectiveness of support [14]. Additionally, incorrectly positioned cannulas lead to turbulent blood flow and cannula 'kicking, thereby increasing the risk of haemolysis and renal dysfunction [15]. More serious complications involve partial or complete cannula dislodgement with resultant rapid loss of ECMO support, air entrainment or catastrophic bleeding [16]. Line movement may also lead to local infection and bloodstream infection by facilitating cannula micromotion with the entry of skin-borne organisms through the insertion site or along the cannula into the bloodstream, as occurs with smaller intravascular catheters $[17,18]$. Routine removal or re-siting of contaminated ECMO lines is not feasible and may be dangerous to the patient [19], and the clinician is sometimes forced into the scenario of premature termination of ECMO support due to cannula site infection. Therefore, adequate securement is paramount in preventing line complications and maintaining ECMO support for its intended duration.

Despite the universal acceptance of the importance of ECMO cannula securement, there are currently no data on best practice for the effective dressing and securement of ECMO cannulas. Currently, in many centres, ECMO cannula sites are covered with transparent 
dressings to protect the site from extrinsic contamination. Securement methods to stabilise ECMO lines and prevent gross movement include tapes, adhesive bandages and sutures, although practice lacks standardisation and no evidence-based recommendations exist. Commercial sutureless securement devices (SSDs) provide a more contemporary approach to ECMO line management at the bedside. However, there is mixed evidence regarding their efficacy in securing intravascular catheters $[20,21]$ and SSDs have never been tested with ECMO cannulas. Medical-grade skin glue (cyanoacrylate), also known as tissue adhesive (TA), has undergone recent investigation as a novel product for securing invasive devices [18, 20, 22-27] and reducing associated infection risk [25, 28, 29]. TA applications for improved intravascular catheter securement compared with transparent dressing include epidural [26], central venous [27], peripheral venous [22, 25] and arterial catheters $[23,24]$. TA also has antimicrobial properties and in vitro testing small-gauge catheters has shown inhibition of Gram-positive organisms, suggesting its potential to reduce the incidence of catheter-associated infection [25, 29].

To date, there has been no published research on ECMO line securement, and TA is untested in large-bore intravascular devices such as ECMO cannulas. We hypothesised that TA could improve ECMO cannula securement and inhibit bacteria at the cannula site. Given the imperative to prevent ECMO line complications, we tested in vitro the safety and feasibility of TA to prevent bacterial colonisation of cannula sites and for cannula site securement when compared with transparent dressing. We additionally compared adhesive bandage and two commercial SSDs for sutureless ECMO tubing securement.

\section{Methods}

This study comprised four parts: (1) assessment of microbiological qualities of TA against standard transparent dressing at the ECMO cannula insertion site; (2) assessment of chemical compatibility between cannula, TA and a TA removal agent; (3) comparison of pull-out strength between transparent dressing and TA at the cannula insertion site; and (4) comparison of pull-out strength between adhesive bandage securement and commercial sutureless securement devices on ECMO circuit tubing.

\section{Microbiological tests}

The ability of TA (Histoacryl; Butyl-cyanoacrylate; B. Braun, Tuttlingen, Germany) and transparent dressing (Opsite Incise Drape; Smith \& Nephew, London, UK) to inhibit Staphylococcus epidermidis (S. epidermidis RB02) migration and colonisation of ECMO cannulas was investigated using methods previously described [25]. The S. epidermidis RB02 used was an isolate from a clinical specimen previously used in similar assays by our team [25]. Briefly, sterile 23F Bio-Medicus femoral (Medtronic Inc., Minneapolis, $\mathrm{MN}$ ) wirewound polyurethane venous cannulas were cut into 5-cm lengths, and each length was aseptically inserted at an angle approximately $30^{\circ}$ into an agar plate containing the $\mathrm{pH}$ indicator bromocresol purple [30]. The cannula plates were separated into three groups, each group comprising of six replicate plates $(n=6)$. Group 1 had transparent dressing (Opsite, $7 \mathrm{~cm} \times 7 \mathrm{~cm}$ ) covering the insertion point; group 2 had TA (Histoacryl, $0.5 \mathrm{~mL}$ ) applied at the insertion point and allowed to dry; group 3 was treated with both TA and transparent dressing. TA and transparent dressings were 
applied according to the manufacturer's instructions. Unsecured cannulas lacking transparent dressing or TA were used as controls $(n=3)$.

A 10- $\mu \mathrm{L}$ aliquot of a S. epidermidis RB02 suspension was applied at the edge of the TA or transparent dressing, or the dressing only for the combined TA and transparent dressing tests. Control plates had the bacteria seeded on the cannula entry point. The bacterial suspension was allowed to dry and was incubated overnight at $37^{\circ} \mathrm{C}$. The plates were scored for bacterial growth every $24 \mathrm{~h}$ up to $72 \mathrm{~h}$. The presence of bacterial growth was determined by $\mathrm{pH}$ indicator dye which changes colour from purple ( $\mathrm{pH}$ 6.8) to yellow $(\mathrm{pH} 5.2)$ when the bacteria ferment glucose in the media and produce acid.

\section{Chemical compatibility tests}

To test chemical compatibility of TA and TA removal agent with ECMO cannulas, 23F Bio-Medicus femoral (Medtronic Inc., Minneapolis, MN) venous cannulas were cut into $15-\mathrm{cm}$ lengths. The central $1-\mathrm{cm}$ cannula section was exposed to Histoacryl or Remove (Smith \& Nephew, Mississauga, ON) adhesive remover wipe per manufacturer instructions for 15 or $60 \mathrm{~min}$ ( $n=6$ per group per exposure time). All cannula sections were then subjected to mechanical testing to measure tensile strength; this was performed using an Instron 5567 (Instron Pty Ltd., High Wycombe, UK) universal testing machine at a crosshead speed of $250 \mathrm{~mm} / \mathrm{min}$. The force $(\mathrm{N})$ needed to produce breakage of the cannula was recorded for every test of each group.

\section{Cannula securement (insertion site) tests}

Adult porcine skin for testing of securement methods was obtained immediately following euthanasia of the animal. Skin sections measuring $13 \mathrm{~cm} \times 20 \mathrm{~cm}$ were cut from a standard area of the animal then washed and dried with paper towel followed by hair removal using a surgical clipper. For each test, the skin section was attached by the edges to a purpose-built metal frame. A simulated ECMO cannula site was created using a modified Seldinger technique; a small incision was made in the centre of the skin section using a scalpel blade, and then, a 15-cm section of a Bio-Medicus Femoral $21 \mathrm{~F}$ venous cannula was inserted through the incision following serial dilatation, allowing the hole to accommodate the cannula whilst ensuring a tight fit. For the TA test group, the cannula was secured with $0.5 \mathrm{~mL}$ of Histoacryl placed around the cannula insertion point and along the cannula to the end of the skin section $(\sim 7 \mathrm{~cm})$, and allowed to dry for $30 \mathrm{~min}$ (Fig. 1a). For the transparent dressing test group, non-glued

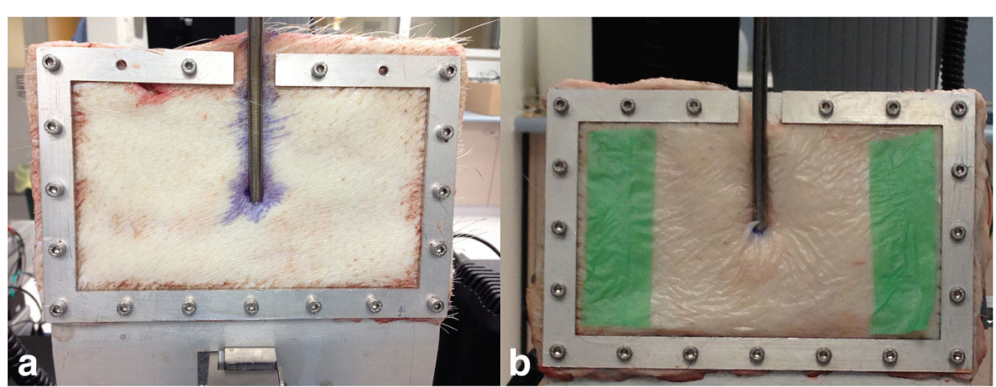

Fig. 1 Simulated ECMO cannula insertion site. Cannula secured with a tissue adhesive, Histoacryl $(n=6)$, and $\mathbf{b}$ transparent dressing, Opsite $(n=6)$ 
cannulas were covered with a single layer of Opsite cut to size $(10 \mathrm{~cm} \times 17 \mathrm{~cm})$ and left untouched for $5 \mathrm{~min}$ after application (Fig. 1b). Six tests were performed for each group. In each test case, the metal frame containing the simulated cannula site was mounted onto the tensile testing machine (Instron 5567) and the pull-out force was measured (tensile force required to produce bond failure under the same conditions as described in 'Chemical compatibility tests').

\section{Tubing securement tests}

Circuit tubing tests were undertaken using porcine skin sections prepared, framed and mounted according to the same method as described above. A simulated ECMO line securement point was created using 20-cm lengths of 3/8-in.-diameter tubing (Medtronic Inc., Minneapolis, MN) secured to the skin in three different groups $(n=6$ for each group). Group 1 was secured with large-sized Grip-lok Universal Securement Device (TIDI Products, Neenah, WI) (Fig. 2a); group 2 was secured with a large-sized MultiFix UniFix Universal Tube and Catheter Securement Band (Midmed Pty Ltd., Murrarie, QLD, Australia) (Fig. 2b); and group 3 was secured to the skin with Tensoplast (BSN Medical, Mt. Waverley, VIC, Australia) elastic adhesive bandage using the method employed at our institution (Fig. 2c): Friars' Balsam (LCM Ltd., Huddersfield, UK) was wiped onto the skin using a gauze pad and allowed to dry (to make the skin 'tacky' and improve adhesion of bandage to the skin); the elastic bandage was stuck onto the skin (along one side of the tubing), looped around the full circumference of the tubing, then stuck to the skin on the opposite side of the looped tape; the bandage was then anchored around the tubing using sutures placed through and around the tape loop (avoiding suturing of the skin) at three points along the tape section to prevent the bandage lifting away from the tubing.

\section{Statistical analysis}

All statistical analyses were performed using Prism 6.0 (Graphpad Software Inc.). Sample size calculations were based on similar testing previously reported [25]. Fisher's exact test was used to statistically evaluate differences in bacterial growth observed between the transparent dressing and TA groups (microbiological tests). All data from mechanical testing (chemical campatibility, cannula securement, and tubing securement tests) were analysed using one-way ANOVA, followed by Tukey's multiple comparison test or $t$ test as appropriate. Statistical significance was defined as $p<0.05$.

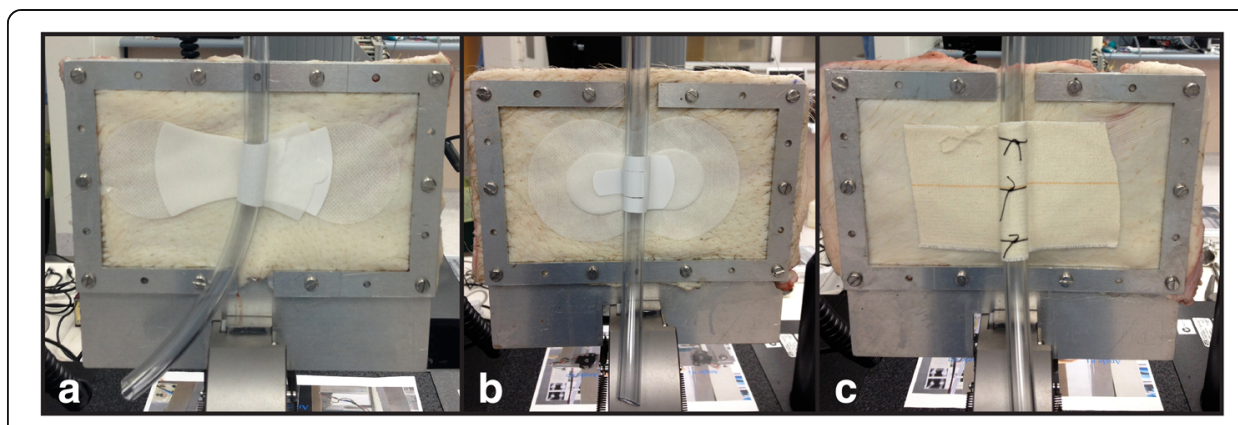

Fig. 2 Skin with ECMO tubing attached and secured. a Grip-lok $(n=6)$. b MultiFix $(n=6)$. c Tensoplast adhesive bandage $(n=6)$ 


\section{Results}

\section{Microbiological tests}

At $24 \mathrm{~h}$ post-inoculation, bacterial growth was not observed in any TA test plates (Fig. 3b) whereas bacterial growth was present under the dressing in all transparent dressing test plates (Fig. 3c) $(p=0.002)$. TA also prevented penetration of bacteria at the cannula insertion point and along the tunnel (in agar) in all tests, when compared with control plates $(p=0.019)$. Bacterial migration to the insertion point did not differ between control and dressing plates with transparent dressing offering no protection from this occurrence $(p=0.167)$. In the combined dressing and TA test plates (Fig. 3d), TA inhibited migration of bacterial growth to the cannula insertion point and along the tunnel with bacterial growth observed only under the transparent dressing. Table 1 indicates the presence or absence of bacterial growth after $72 \mathrm{~h}$ of observation.

\section{Chemical compatibility tests}

Compared with control, cannula tensile strength was not reduced with the TA (132 vs $128 \mathrm{~N})$ or TA remover agent $(132 \mathrm{vs} 134 \mathrm{~N})$ at the 15 -min exposure time $(p=0.57)$. However, increasing the TA remover agent exposure time to $1 \mathrm{~h}$ significantly weakened the cannula (132 vs $87 \mathrm{~N}, p<0.01)$.

\section{Cannula securement (insertion site) tests and tubing securement tests}

TA significantly increased the pull-out force required to remove the cannula from the skin when compared with transparent dressing (62.8 vs $15.2 \mathrm{~N}, p<0.0001$; Fig. 4a). The force required to remove the tubing from the skin with both Grip-lok device $(92.0 \mathrm{~N})$ and MultiFix device $(94.8 \mathrm{~N})$ was very similar and was significantly increased compared with Tensoplast adhesive bandage (56.2 N) $(p<0.01$; Fig. 4 b).

\section{Discussion}

This in vitro study demonstrated that TA is effective in providing a barrier for the prevention of bacterial migration to the ECMO cannula insertion site; TA significantly increases the force required to dislodge the cannula from the insertion site and, when used in combination with a SSD securing the circuit tubing, could substantially reduce

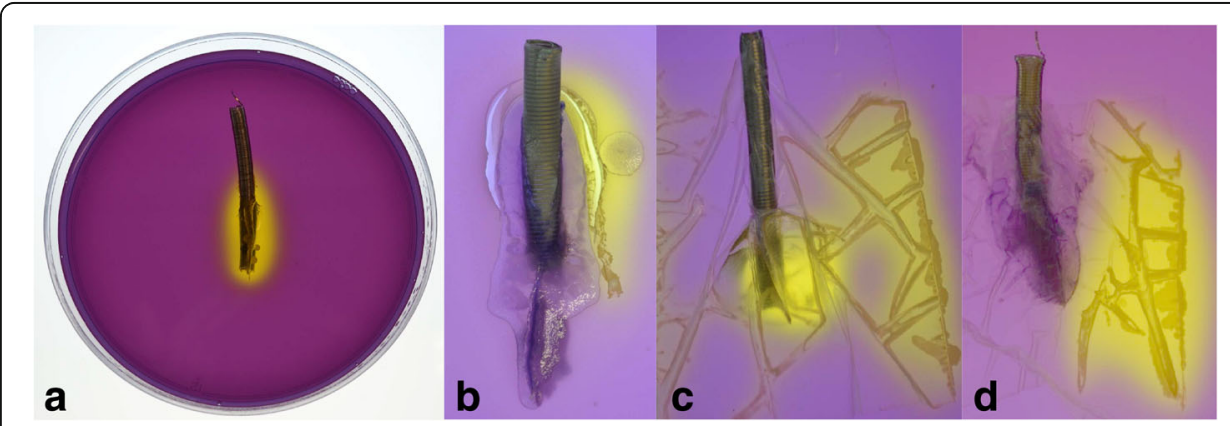

Fig. 3 Microbiological test results. a Control plate: S. epidermidis growth on pH indicator agar. b TA applied at insertion site: TA inhibits S. epidermidis growth along the TA edge to the insertion point. c Transparent dressing applied over insertion site: S. epidermidis growth under the dressing, at the cannula insertion point and along the cannula dressing tunnel. d TA + transparent dressing: S. epidermidis growth under the dressing but inhibited beyond the TA edge. TA, tissue adhesive 
Table $1 \mathrm{~S}$. epidermidis growth surrounding ECMO cannulas and securement product at $72 \mathrm{~h}$ post-inoculation

\begin{tabular}{lllll}
\hline Securement product & $\begin{array}{l}\text { Edge of securement } \\
\text { product }\end{array}$ & $\begin{array}{l}\text { Underneath securement } \\
\text { product }\end{array}$ & $\begin{array}{l}\text { Cannula insertion } \\
\text { point }\end{array}$ & $\begin{array}{l}\text { Along cannula } \\
\text { tunnel }\end{array}$ \\
\hline Histoacryl $(n=6)$ & + & - & - & - \\
Opsite $(n=6)$ & + & + & + & + \\
Histoacryl and Opsite $(n=6)$ & - (Histoacryl) & - (Histoacryl) & - & - \\
& + (Opsite) & + (Opsite) & & + \\
Unsecured $(n=3)$ & N/A & N/A & + & + \\
\hline
\end{tabular}

"+" growth at $72 \mathrm{~h}$, " -" absence of growth at $72 \mathrm{~h}$

the risk of accidental cannula movement and dislodgement. We found that TA prevented bacterial migration to the site of insertion and along the cannula tunnel, alone or in combination with transparent dressing. Additionally, TA was shown to be a superior option for ECMO cannula securement when compared to transparent dressing, which is commonly used to dress and secure cannulas at the point of percutaneous insertion. We established that the two commercial SSDs were more efficacious than the adhesive bandage method (Tensoplast) used at our institution to secure ECMO circuit tubing. Our findings suggest that TA may be useful in the bedside management of ECMO lines, both to prevent or minimise the potential for infection and to improve sutureless line securement.

To our knowledge, TA has not been tested as a bacterial inhibitor with ECMO cannulas. The complete capacity of TA to prevent bacterial migration in this in vitro study has significant potential in the clinical setting. When used to seal the ECMO cannula insertion site, TA effects may reduce extraluminal contamination via a bactericidal effect or a physical barrier effect on bacterial translocation at the skin puncture [29]. Therefore, TA has the potential to reduce localised and bloodstream infection in ECMO, and subsequently may decrease ICU stays, hospital stays and healthcare costs.

Our results also showed that neither TA nor TA remover wipe (Remove wipes) applied for $15 \mathrm{~min}$ weakened the cannula. However, exposure to TA remover wipe weakened the cannula after $60 \mathrm{~min}$; therefore, all residual products must be removed from the ECMO cannula after TA removal. Avoiding prolonged contact and thoroughly wiping the area with normal saline to remove TA remover wipe residue must be key elements of cannula site care protocols. The manufacturer's instructions regarding the
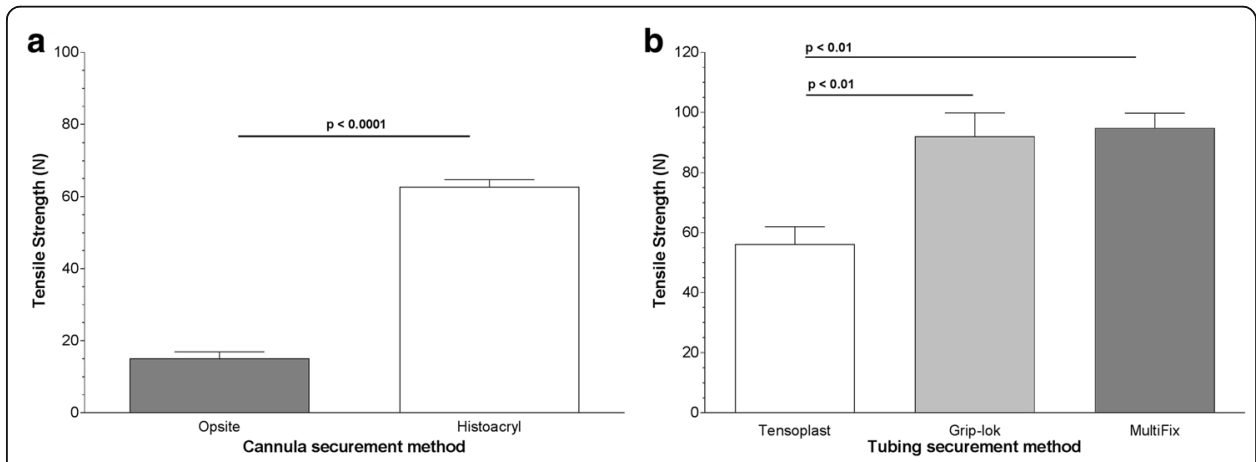

Fig. 4 Mechanical test results. a Cannula securement comparing transparent dressing (Opsite) with TA (Histoacryl). b Tubing securement comparing adhesive bandage (Tensoplast) with SSD (Grip-lok and MultiFix). TA, tissue adhesive; SSD, sutureless securement device 
removal of TA (Histoacryl) state that acetone may be used to remove residual product; however, this was not tested in this study as the investigators felt it would be inappropriate to use acetone on the cannulation site.

In testing the securement properties of TA at the site of cannula insertion, we found TA to be significantly stronger than transparent dressing. Other research shows TA to be a promising novel solution for intravascular device securement $[18,20,23,24]$. Compared with transparent dressing, TA may have benefits in reduced ECMO cannula migration, as well as reduced infection risk by limiting pistoning or micromotion of the cannula and subsequent introduction of bacteria $[17,18]$. Its clinical application would be advantageous for femoral cannulas given that peripheral cannulation for ECMO commonly involves the femoral vessels [31] and this location is a greater risk factor for colonisation and/or bloodstream infection compared with internal jugular sites in adults [32]. With regard to securement of the ECMO tubing, both of the commercial SSDs tested were significantly stronger than the method using adhesive bandage (Tensoplast). The greater tensile strength and therefore ability to limit gross line movement suggests SSDs could offer a safer clinical approach to reducing the risk of acutely life-threatening or fatal outcomes of accidental decannulation [33, 34]. SSDs have undergone limited clinical testing, but they appear safe, feasible and acceptable for central catheters [20]. The benefits of SSDs and TA in ECMO are summarised in Table 2.

The current study suggests that TA is a promising, simple alternative to traditional dressing methods and suturing which is itself associated with infection risk. We propose that the combined use of TA at the insertion site with SSDs along the ECMO tubing provides a feasible line management strategy which can be easily implemented at the bedside to prevent complications. Our findings have particular relevance to centres performing peripheral cannulation by percutaneous Seldinger technique since a key rationale of this practice is to avoid skin suturing and reduce insertion site bleeding $[16,35]$. Our research highlights the importance of further investigation into the most effective methods for sutureless securement in this context, especially with the trend to increase patient mobility on ECMO [36, 37]; the need to transfer these patients for scanning or procedures; and the preference for multiport drainage cannulas which can rapidly entrain air through side holes should outward migration from the vessel occur [38]. A targeted research program investigating dressing and securement options is vital in providing valuable evidence to guide global practice in this area.

There were limitations to this study. Firstly, we tested only S. epidermidis due to its association with bloodstream infection during ECMO and its reported association with culture confirmed ECMO cannula infection [4]. We tested S. aureus in a previous laboratory study with the same results as S. epidermidis [25]. Secondly, microbiological and mechanical testing was performed using only one type of TA (butyl-cyanoacrylate) as our previous testing [25] demonstrated its superiority over octyl-cyanoacrylate. Thirdly, mechanical testing of the cannulas and tubing was performed separately rather than together as one continuous ECMO line. There are limitations in testing two mechanical systems in series, due to different strengths, inevitably that the load will not be shared evenly between the two sites, meaning one will always fail before the other at a similar failure force of that part on its own. Lastly, the use of TA to secure ECMO cannulas would not be appropriate for central ECMO cannulations therefore our findings could only be generalisable to peripheral cannulations. 


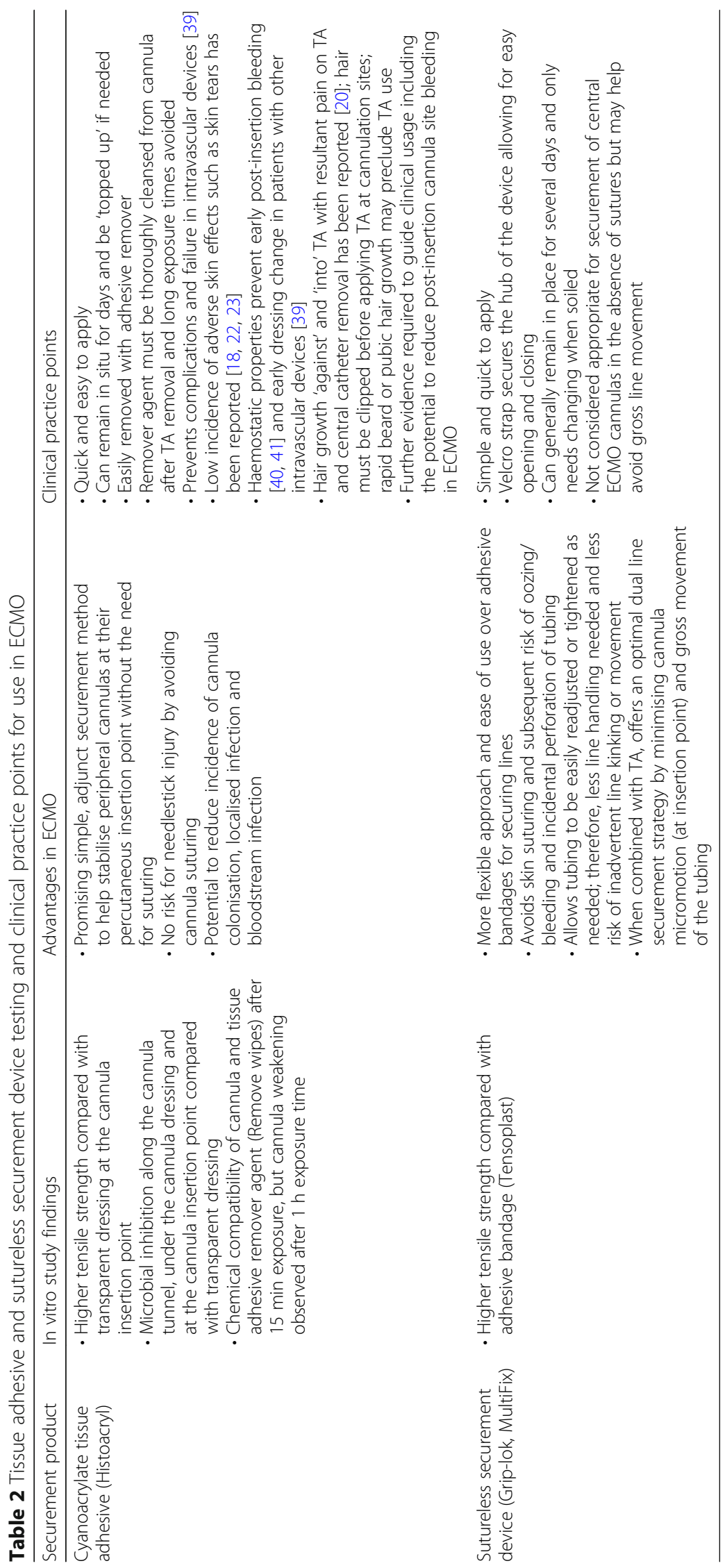




\section{Conclusions}

TA appears promising as a simple infection prevention and adjunct securement method for ECMO lines. Moreover, the combined use of TA at the cannula entry point with a sutureless device for tubing securement could provide an optimal overall strategy for line stabilisation, with the potential to reduce ECMO line-associated complications. A sufficiently powered randomised controlled trial will determine if the pre-clinical findings reported here translate into an effective strategy to reduce cannula-associated infection and cannula malposition or dislodgement.

Abbreviations

ECMO: Extracorporeal membrane oxygenation; SSD: Sutureless securement device; TA: Tissue adhesive

\section{Acknowledgements}

The authors thank Dr. Barbara Lingwood of the Perinatal Research Centre (University of Queensland) for providing the porcine skin and the Queensland University of Technology for the use of the Instron testing machine and laboratory facilities. JFF acknowledges his Queensland Health Office of Health and Medical Research Fellowship and his membership of the International ECMO Network (ECMONet).

\section{Funding}

This study had no manufacturer funding or involvement. It was funded by a competitive grant from The Prince Charles Hospital Foundation (NI2012-125) who had no part in the study design, data collection or manuscript preparation.

\section{Availability of data and materials}

The datasets generated and/or analysed during the current study are available from the corresponding author on a reasonable request.

\section{Authors' contributions}

TB incepted the study, wrote the protocol, performed the data collection, interpreted the data and prepared the manuscript. AC and JFF assisted with the protocol development, interpreted the data and assisted in the manuscript preparation. DJS performed the microbiological testing. DJM assisted with the protocol development, performed the statistical analysis for the microbiological testing and assisted in the manuscript preparation. KRD performed the data collection and statistical analysis for the tensile strength and chemical compatibility testing. All authors read and approved the final manuscript.

\section{Ethics approval and consent to participate}

Ethical approval for the collection of porcine tissue was approved by the University of Queensland Animal Ethics Committee (UQCCR/060/12/NHMRC). The Queensland University of Technology Research Ethics Unit (1200000140) approved the use of tissue in research described here.

\section{Consent for publication}

Not applicable.

\section{Competing interests}

The authors declare that they have no competing interests.

\section{Publisher's Note}

Springer Nature remains neutral with regard to jurisdictional claims in published maps and institutional affiliations.

\section{Author details}

${ }^{1}$ Critical Care Research Group, The Prince Charles Hospital and University of Queensland, Level 3 Clinical Sciences Building, Rode Rd, Chermside 4032, Queensland, Australia. ${ }^{2}$ Bacterial Pathogenesis Laboratory, Queensland Institute of Medical Research, Herston Rd, Herston 4006, Queensland, Australia. ${ }^{3}$ Inflammation and Healing Research Cluster, Faculty of Science, Health, Education and Engineering, University of the Sunshine Coast, 90 Sippy Downs Dr, Sippy Downs 4556, Queensland, Australia.

Received: 12 September 2017 Accepted: 28 February 2018

Published online: 12 March 2018

\section{References}

1. Gaffney A, Wildhirt S, Griffin M et al (2010) Extracorporeal life support. BMJ 341:982-986

2. Fraser JF, Shekar K, Diab S et al (2012) ECMO_the clinician's view. ISBT Sci Ser 7:82-88

3. Bizzarro M, Conrad S, Kaufman D et al (2011) Infections acquired during extracorporeal membrane oxygenation in neonates, children, and adults. Pediatr Crit Care Med 12:277-281

4. Schmidt M, Bréchot N, Hariri S et al (2012) Nosocomial infections in adult cardiogenic shock patients supported by venoarterial extracorporeal membrane oxygenation. Clin Infect Dis 55:1633-1641 
5. Pieri M, Agracheva N, Fumaglli L et al (2013) Infections occurring in adult patients receiving mechanical circulatory support: the two-year experience of an Italian national referral tertiary care center. Med Int 37:468-475

6. Meyer DM, Jessen ME, Eberhart RC (1995) Neonatal extracorporeal membrane oxygenation complicated by sepsis. Ann Thorac Surg 59:975-980

7. Burket J, Bartlett R, Vender Hyde K et al (1999) Nosocomial infections in adult patients undergoing extracorporeal membrane oxygenation. Clin Infect Dis 28:828-833

8. Hsu MS, Chiu KM, Huang YT et al (2009) Risk factors for nosocomial infection during extracorporeal membrane oxygenation. J Hosp Infect 73:210-216

9. Sun HY, Ko WJ, Tsai PR et al (2010) Infections occurring during extracorporeal membrane oxygenation use in adult patients. J Thorac Cardiovasc Surg 140:1125-1132

10. Aubron C, Cheng AC, Pilcher D et al (2013) Infections acquired by adults who receive extracorporeal membrane oxygenation: risk factors and outcome. Infect Control Hosp Epidemiol 34:24-30

11. Montgomery VL, Strotman JM, Ross MP (2000) Impact of multiple organ system dysfunction and nosocomial infections on survival of children treated with extracorporeal membrane oxygenation after heart surgery. Crit Care Med 28:526-531

12. Australia and New Zealand Extracorporeal Membrane Oxygenation (ANZ ECMO) Influenza Investigators, Davies A, Jones D et al (2009) Extracorporeal membrane oxygenation for 2009 influenza A (H1N1) acute respiratory distress syndrome. JAMA 302:1888-1895

13. Combes A, Leprince P, Luyt CE et al (2008) Outcomes and long-term quality of life of patients supported by extracorporeal membrane oxygenation for refractory cardiogenic shock. Crit Care Med 36: 1404-1411

14. Sidebotham D, McGeorge A, McGuinness S et al (2010) Extracorporeal membrane oxygenation for treating severe cardiac and respiratory failure in adults: part 2-technical considerations. J Cardiothorac Vasc Anesth 24:164-172

15. Lehle K, Philipp A, Zeman F et al (2015) Technical-induced hemolysis in patients with respiratory failure supported with veno-venous ECMO—prevalence and risk factors. PLoS One 10:e0143527

16. Butt W, Heard M, Peek G (2013) Clinical management of the extracorporeal membrane oxygenation circuit. Pediatr Crit Care Med 14:S13-S19

17. Frey A, Schears $G$ (2006) Why are we stuck on tape and suture? A review of catheter securement devices. J Infus Nurs 29:34-38

18. Marsh N, Webster J, Flynn J et al (2015) Securement methods for peripheral venous catheters to prevent failure: a randomised controlled pilot trial. J Vasc Access 16:237-244

19. Extracorporeal Life Support Organization (2017) ELSO Guidelines for Cardiopulmonary Extracorporeal Life Support. Version 1.4. Ann Arbor, MI, USA. Available via https:/www.elso.org/Resources/Guidelines.aspx. Accessed 3 Sept 2017.

20. Rickard CM, Edwards M, Spooner AJ et al (2016) A 4-arm randomized controlled pilot trial of innovative solutions for jugular central venous access device securement in 221 cardiac surgical patients. I Crit Care 36:35-42

21. Yamamoto AJ, Solomon JA, Soulen MC et al (2002) Sutureless securement device reduces complications of peripherally inserted central venous catheters. J Vasc Interv Radiol 13:77-81

22. Bugden S, Shean K, Scott M et al (2016) Skin glue reduces the failure rate of emergency department-inserted peripheral intravenous catheters: a randomized controlled trial. Ann Emerg Med 68:196-201

23. Edwards M, Rickard CM, Rapchuk I et al (2014) A pilot trial of bordered polyurethane dressings, tissue adhesive and sutureless devices compared with standard polyurethane dressings for securing short-term arterial catheters. Crit Care Resusc 16:175-183

24. Reynolds H, Taraporewalla K, Tower M et al (2015) Novel technologies can provide effective dressing and securement for peripheral arterial catheters: a pilot randomised controlled trial in the operating theatre and the intensive care unit. Aust Crit Care 28:140-148

25. Simonova G, Rickard CM, Dunster KR et al (2012) Cyanoacrylate tissue adhesives-effective securement technique for intravascular catheters: in vitro testing of safety and feasibility. Anaesth Intensive Care 40:460-466

26. Wilkinson JN, Fitz-Henry J (2008) Securing epidural catheters with Histoacryl glue. Anaesthesia 63:324

27. Wilkinson JN, Sheikh N, Jayamaha J (2007) Tissue adhesive as an alternative to sutures for securing central venous catheters. Anaesthesia 62:969-970

28. Bookland M, Sukul V, Connolly P (2014) Use of cyanoacrylate skin adhesive to reduce external ventricular drain infection rates. J Neurosurg 121:189-194

29. Wilkinson JN, Chikhani M, Mortimer K et al (2008) The antimicrobial effect of Histoacryl skin adhesive. Anaesthesia 63:1382-1384

30. Bhende S, Rothenburger S, Spangler D et al (2002) In vitro assessment of microbial barrier properties of Dermabond topical skin adhesive. Surg Infect 3:251-257

31. Allen S, Holena D, McCunn M et al (2011) A review of the fundamental principles and evidence base in the use of extracorporeal membrane oxygenation (ECMO) in critically ill adult patients. J Intensive Care Med 26:13-26

32. O'Grady NP, Alexander M, Burns LA et al (2011) Guidelines for the prevention of intravascular catheter-related infections. Am J Infect Control 39:S1-S34

33. Belohlávek J, Rohn V, Tosovsky J et al (2011) A review of a newly established ECMO program in a university affiliated cardiac center. J Cardiovasc Surg 52:445-451

34. Mullany DV, Bull TN, Hunt W et al (2012) Outcomes of the first 30 cases of an adult extracorporeal membrane oxygenation program: strategies to manage the "learning curve" and implications for intensive care unit risk adjustment models. Crit Care Resusc 14:119-129

35. Combes A, Bacchetta M, Brodie D et al (2012) Extracorporeal membrane oxygenation for respiratory failure in adults. Curr Opin Crit Care 18:99-104

36. Dalton HJ (2011) Extracorporeal life support: moving at the speed of light. Respir Care 56:1445-1453

37. MacLaren G, Combes A, Bartlett RH (2012) Contemporary extracorporeal membrane oxygenation for adult respiratory failure: life support in the new era. Intensive Care Med 38:210-220 
38. Sidebotham D, Allen S, McGeorge A et al (2012) Venovenous extracorporeal membrane oxygenation in adults: practical aspects of circuits, cannulae, and procedures. J Cardiothorac Vasc Anesth 26:893-909

39. Corley A, Marsh N, Ullman AJ et al (2017) Tissue adhesive for vascular access devices: who, what, where and when? Br J Nurs 26:S4-S17

40. Scoppettuolo G, Annetta M, Marano C et al (2013) Cyanoacrylate glue prevents early bleeding of the exit site after CVC or PICC placement. Crit Care 17:P174

41. Scoppettuolo G, Dolcetti L, Emoli A et al (2015) Further benefits of cyanoacrylate glue for central venous catheterisation. Anaesthesia 70:758

\section{Submit your manuscript to a SpringerOpen ${ }^{\circ}$} journal and benefit from:

- Convenient online submission

- Rigorous peer review

- Open access: articles freely available online

- High visibility within the field

- Retaining the copyright to your article

Submit your next manuscript at $>$ springeropen.com 